in vivo $35: 393-399(2021)$

doi:10.21873/invivo.12270

\title{
The Epidemiology, Staging and Outcomes of Sarcomatoid Hepatocellular Carcinoma: A SEER Population Analysis
}

\author{
DIMITRIOS GIANNIS ${ }^{1 *}$, SARA MORSY ${ }^{2 *}$, GEORGIOS GEROPOULOS ${ }^{3}$, \\ STEPAN M. ESAGIAN ${ }^{4}$, GEORGIOS S. SIOUTAS ${ }^{4}$ and DIMITRIOS MORIS ${ }^{5}$ \\ ${ }^{1}$ Faculty of Medicine, School of Health Sciences, University of Thessaly, Larissa, Greece; \\ ${ }^{2}$ Faculty of Medicine, Tanta University, Tanta, Egypt; \\ ${ }^{3}$ Thoracic Surgery Department, University College London Hospitals, NHS; \\ Foundation Trust, London, U.K.; \\ ${ }^{4}$ Faculty of Medicine, Democritus University of Thrace, Dragana, Alexandroupolis, Greece; \\ ${ }^{5}$ Duke Surgery, Duke University Medical Center, Durham, NC, U.S.A.
}

\begin{abstract}
Background: Hepatocellular carcinoma (HCC) subtypes differ in terms of histopathology and prognosis. Sarcomatoid HCC is rare and literature concerning the survival of patients with sarcomatoid HCC is scarce. Materials and Methods: Data of patients with sarcomatoid HCC, diagnosed from 1989 to 2016, were extracted from the Surveillance, Epidemiology and End Results (SEER) database. We evaluated the baseline and tumor related data, overall survival (OS), disease-specific survival and the performance (Harrell's concordance index - OS c-index) of the eighth edition of the American Joint Committee on Cancer TNM staging system (AJCC8). In addition, univariate and multivariate forward stepwise cox regression analyses were performed to identify factors associated with increased risk of death. Results: The SEER cohort consisted of 71 patients, mostly males ( $n=49$, $69.0 \%)$, of White race $(n=51,71.8 \%)$ and the most common stage at presentation was stage IVB $(n=30,42.3 \%)$. The overall predictive ability of AJCC8 was mediocre, with an OS $c$ index $=0.577$ (SE=0.048). Surgery (hazard ratio=0.25, $p<0.001)$ was significantly associated with reduced risk of death. Advanced TNM stage was not associated with increased risk of death. Conclusion: Sarcomatoid HCC, a rare subtype of $H C C$, is associated with poor outcomes in terms of overall and
\end{abstract}

This article is freely accessible online.

*These Authors have equally contributed to the manuscript and share first co-authorship.

Correspondence to: Dimitrios Moris (ORCID: 0000-0002-52760699), Duke Surgery, Duke University Medical Center, Durham, NC, U.S.A. E-mail: dimmoris@yahoo.com

Key Words: Hepatocellular carcinoma, SEER, sarcomatoid, AJCC. disease-specific survival across all disease stages. Surgery seems to be of utmost importance. The eighth edition of the AJCC8 for HCC underperforms in predicting the survival of patients with sarcomatoid subtype.

Hepatocellular carcinoma (HCC) comprises approximately $70-80 \%$ of all primary liver malignant neoplasms. HCC is globally the fourth most common cause of cancer-related death worldwide and the majority of cases occur in Asia $(72 \%)$, whereas European (10\%), African (7.8\%) and North American $(5.1 \%)$ populations are less affected (1). Males are predominantly affected compared to females, with a ratio of approximately 2.5-3.0 $(1,2)$ In the United States, HCC occurs with an incidence of up to approximately six cases per 100,000 population at risk $(3,4)$.

HCC treatment is multimodal but the only curative-intent treatments include complete resection of early-stage tumors or liver transplantation (5). Other treatment modalities, such as radiofrequency ablation, transarterial chemoembolization and newer chemotherapeutic agents, including sorafenib, have been utilized with variable but non-curative results $(3,6,7)$.

$\mathrm{HCC}$ is categorized into different variants and some of them are associated with a worse prognosis, higher rate of recurrence and specific gene mutations that significantly affect management in the era of precision medicine (8-11). Previously, median survival was estimated to be up to 28 months but with improved patient selection processes and appropriate curative treatment, median survival currently exceeds 36 months $(5,12)$. Potential implications of patient selection include the classification of patients according to histological subtype, the genetic profile of the tumor and targeted individualized treatments.

Sarcomatoid hepatocellular carcinoma - also known as spindle-cell HCC - is a rare type consisting of epithelial and mesenchymal spindle cells and accounts for approximately 
1.8-3.9\% of HCC cases (13-16). The 2010 World Health Organization classification of gastrointestinal tumors includes sarcomatoid HCC under the spectrum of aggressive liver tumors, such as fibrolamellar carcinoma, scirrhous HCC, undifferentiated carcinoma and lymphoepitheliomalike carcinoma (17). It has been shown that sarcomatoid HCC is a discrete HCC subtype in terms of patient presentation at diagnosis (larger tumors, worse grade) and prognosis (worse survival per stage) in comparison to HCC with classic histology $(8,14)$. Liao et al. reported 1-, 3- and 5- year survival of $45.0 \%, 17.5 \%$ and $10 \%$, respectively, and increased recurrence and extrahepatic metastasis in sarcomatoid HCC compared to non-sarcomatoid HCC (10).

Treatment choice and appropriate counseling according to stage is of extreme importance. The Union for International Cancer Control and American Joint Committee on Cancer (AJCC) developed the TNM staging system in order to standardize evaluation of disease progression, predict survival and facilitate appropriate treatment planning. Since its first edition in 1977, this tumor classification system is modified and updated regularly every few years through the supplementation of new data (18). The most recent edition of the TNM classification, the eighth (AJCC8), was published in 2016 (19).

The objective of our study was to summarize the epidemiology and outcomes as well as to assess the performance of AJCC8 utilizing data for patients with sarcomatoid HCC derived from the Surveillance, Epidemiology and End Results (SEER) database.

\section{Materials and Methods}

Data sources and samples. Data on sarcomatoid HCC were extracted from the SEER database between 1989-2016 with the use of SEER*stat 8.3.6 software (Surveillance Research Program, National Cancer Institute, Bethesda, MD, USA). All patients diagnosed with sarcomatoid $\mathrm{HCC}$ were identified through the third edition of the International Classification of Disease for Oncology site code for sarcomatoid HCC (C22.0) and histology code 8173 (sarcomatoid/spindle-cell HCC) carcinoma and were included in the analysis. T Classification was identified based on CS_Extension and $\mathrm{N}$ classification was identified through the CS_Lymph_Nodes, RX Sum-Scope_Reg_LN_Sur_ (2003+) and the regional node positivity code (Regional_Nodes_Positive). M Staging for the AJCC8 classification was extracted using CS metastasis codes (CS_Mets_At_Dx and CS_Mets_Eval). TNM staging was summarized according to the AJCC8 system (19).

SEER data such as age, sex, race, marital status, diagnosis, tumor site, TNM stage, grade, chemotherapy treatment, radiation, surgical treatment and survival (months) were extracted.

Statistical analysis and outcomes of interest. Summary statistics are reported as absolute values with percentages (categorical variables) or mean values with standard deviation (SD) (continuous variables).

Overall and disease-specific survival, based on the date of last follow-up or death as the event of interest, was estimated with the Kaplan-Meier method. The discriminatory ability of AJCC8 was
Table I. Surveillance, Epidemiology, and End results database: Baseline characteristics and tumor related data of patients with sarcomatoid hepatocellular carcinoma (HCC) $(n=71)$.

\begin{tabular}{|c|c|c|}
\hline \multicolumn{2}{|l|}{ Characteristic } & \multirow{2}{*}{$\begin{array}{c}\text { Value } \\
65.7 \pm 11.5\end{array}$} \\
\hline Age, years & Mean \pm SD & \\
\hline \multirow[t]{2}{*}{ Gender n (\%) } & Male & $49(69.0 \%)$ \\
\hline & Female & $22(31.0 \%)$ \\
\hline \multirow[t]{3}{*}{ Race n (\%) } & White & $51(71.8 \%)$ \\
\hline & Black & $11(15.5 \%)$ \\
\hline & Asian or Pacific Islander & $9(12.7 \%)$ \\
\hline \multirow[t]{5}{*}{ Marital status n (\%) } & Married & $40(56.3 \%)$ \\
\hline & Single & $12(16.9 \%)$ \\
\hline & Widowed & $10(14.1 \%)$ \\
\hline & Divorced & $8(11.3 \%)$ \\
\hline & Unknown & $1(1.4 \%)$ \\
\hline \multirow[t]{5}{*}{ Grade n (\%) } & Well differentiated & $1(1.4 \%)$ \\
\hline & Moderately differentiated & $3(4.2 \%)$ \\
\hline & Poorly differentiated & $26(36.6 \%)$ \\
\hline & Anaplastic & $6(8.5 \%)$ \\
\hline & Unknown & $35(49.3 \%)$ \\
\hline \multirow{3}{*}{$\begin{array}{l}\text { Diagnostic } \\
\text { confirmation } \mathrm{n}(\%)\end{array}$} & Positive histology & $68(95.8 \%)$ \\
\hline & Clinical diagnosis only & $2(2.8 \%)$ \\
\hline & Positive exfoliative cytology & $1(1.4 \%)$ \\
\hline Survival, months & $\mathrm{Mean} \pm \mathrm{SD}$ & $8.9 \pm 20.8$ \\
\hline \multirow[t]{6}{*}{ T-Stage n $(\%)$} & $\mathrm{T} 1 \mathrm{a}$ & $4(5.6 \%)$ \\
\hline & $\mathrm{T} 1 \mathrm{~b}$ & $11(15.5 \%)$ \\
\hline & $\mathrm{T} 2$ & $8(11.3 \%)$ \\
\hline & T3 & $18(25.3 \%)$ \\
\hline & $\mathrm{T} 4$ & $19(26.8 \%)$ \\
\hline & Unknown & $11(15.5 \%)$ \\
\hline \multirow[t]{3}{*}{ N-Stage n (\%) } & No & $36(50.7 \%)$ \\
\hline & $\mathrm{N} 1$ & $15(21.1 \%)$ \\
\hline & Unknown & $20(28.2 \%)$ \\
\hline \multirow[t]{3}{*}{ M-Stage n (\%) } & M0 & $30(42.3 \%)$ \\
\hline & M1 & $30(42.3 \%)$ \\
\hline & Unknown & $11(15.4 \%)$ \\
\hline \multirow[t]{8}{*}{ TNM Stage n (\%) } & IA & $2(2.8 \%)$ \\
\hline & IB & $5(7.0 \%)$ \\
\hline & II & $3(4.2 \%)$ \\
\hline & IIIA & $7(9.9 \%)$ \\
\hline & IIIB & $5(7.0 \%)$ \\
\hline & IVA & $2(2.8 \%)$ \\
\hline & IVB & $30(42.3 \%)$ \\
\hline & Unknown & $17(23.9 \%)$ \\
\hline \multirow[t]{2}{*}{ Surgery n (\%) } & Yes & $19(26.8 \%)$ \\
\hline & No & $52(73.2 \%)$ \\
\hline \multirow[t]{3}{*}{ Radiation n (\%) } & Beam radiation & $4(5.6 \%)$ \\
\hline & Radioactive implants & $1(1.4 \%)$ \\
\hline & None & $66(93.0 \%)$ \\
\hline \multirow[t]{2}{*}{ Chemotherapy n (\%) } & Yes & $18(25.4 \%)$ \\
\hline & No & $53(74.6 \%)$ \\
\hline \multirow[t]{3}{*}{ Cause of death $n(\%)$} & Alive (at follow-up) & $11(15.5 \%)$ \\
\hline & $\mathrm{HCC}$ & $44(62.0 \%)$ \\
\hline & Other cause & $16(22.5 \%)$ \\
\hline
\end{tabular}

SD: Standard deviation.

evaluated with Harrell's concordance index (c-index) (20, 21). All statistical analyses were performed with R-Project ( $\mathrm{R}$ version 3.6.1). Classification of patients according to cause of death was performed 


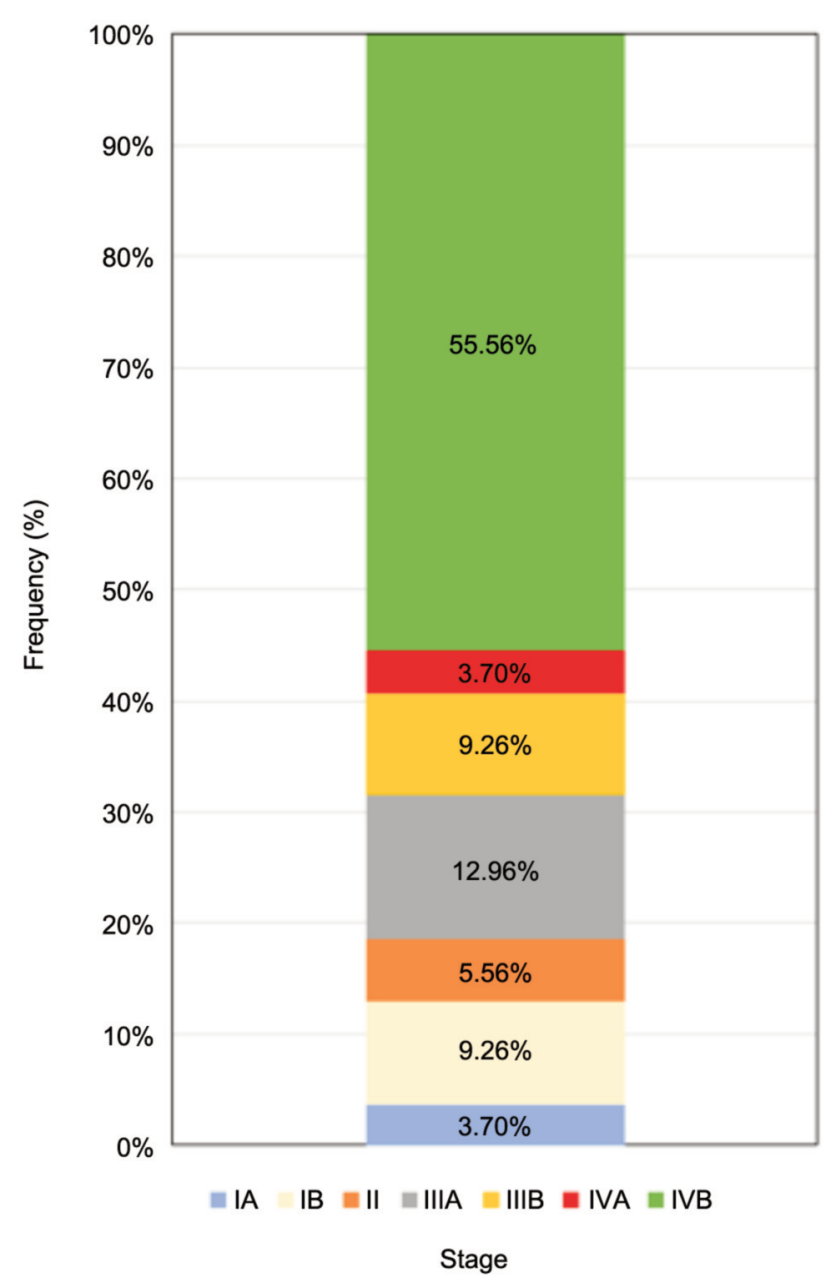

Figure 1. Distribution of patients with sarcomatoid hepatocellular carcinoma in the Surveillance, Epidemiology, and End results database by stage according to the eighth edition of the American Joint Commission on Cancer classification system (19) $(n=54)$.

to identify any difference in survival between patients with disease of different AJCC stages. Univariate and multivariate forward stepwise Cox regression analyses were used to identify significant predictors for survival and the corresponding risk was expressed as a hazard ratio (HR) with 95\% confidence interval (95\% CI) and level of statistical significance $(22,23)$. Whenever applicable, a $p$ value of less than 0.05 was considered as the cut-off level of statistical significance.

\section{Results}

Cohort characteristics. The SEER cohort consisted of 71 patients diagnosed with sarcomatoid HCC at a mean age of $65.7 \pm 11.5$ years (Table I). The majority of patients were male $(n=49,69.0 \%)$ and of White race $(n=51,71.8 \%)$. At presentation, the most common stage by AJCC8 was IVB $(n=30,42.3 \%$ of the total cohort and $55.56 \%$ of patients with

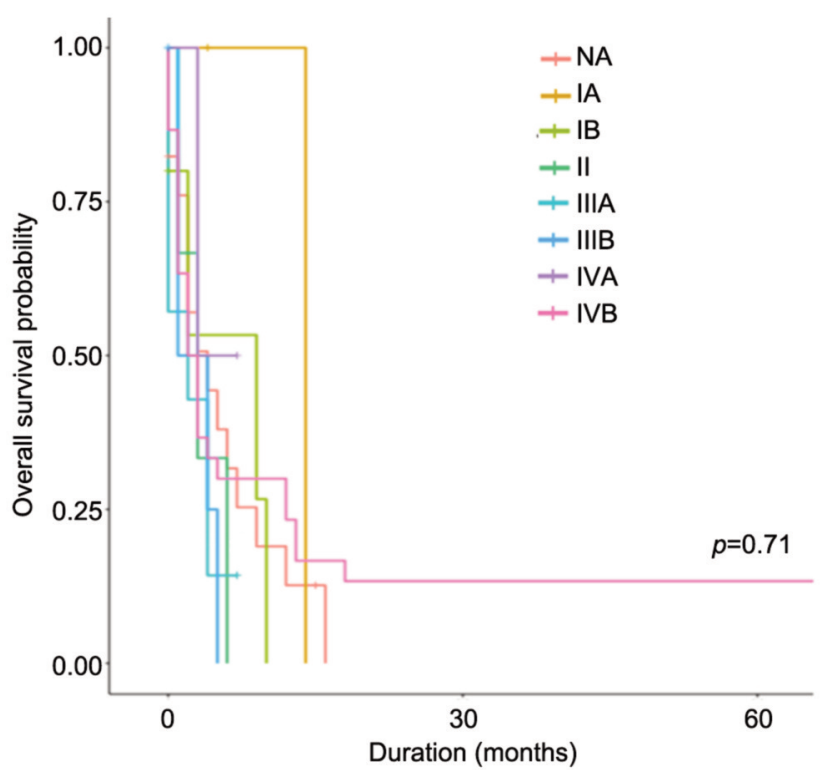

Figure 2. Kaplan-Meier curve of overall survival of patients with sarcomatoid hepatocellular carcinoma in the Surveillance, Epidemiology, and End results database according to stage by the eighth edition of the American Joint Commission on Cancer classification system (19).

known stage) (Table I; Figure 1). Positive histology was reported as the method of diagnosis in the majority of cases $(\mathrm{n}=68,95.8 \%)$ and almost half of the tumors were graded as poorly differentiated or anaplastic $(n=32,45.0 \%)$. Most patients were not surgically treated $(n=52,73.2 \%)$, the majority did not receive radiation therapy $(n=66,93 \%)$ and $74.6 \%$ did not receive chemotherapy.

Survival analysis and performance of AJCC8 classification. In this cohort, $84.5 \%$ of patients died due to sarcomatoid HCC $(n=44,62.0 \%)$ or other causes $(n=16,22.5 \%)$; the mean survival time was 8.9 months and the median survival was 3 months. The 6-, 12-, and 18- month OS rates were $29.3 \%, 17.4 \%$ and $8.11 \%$, respectively. The median DSS was $3(95 \% \mathrm{CI}=2-4)$ months.

The median OS for each stage was 14 months for IA, 4 months for IB, 4 months for II, 5 months for IIIA, 4 months for IIIB, months for IVA 6 and 2 months IVB (Figure 2). The median DSS for each stage was 14 months for IA, 0 months for IB, 2 months for II, 2 months for IIIA, 4 months for IIIB, 3 months for IVA and 3 months for IVB (Figure 3). Subgroup analysis of patients who died due to $\mathrm{HCC}$ revealed no significant difference in survival between patients of different by AJCC8 TNM stage $(p=0.7)$ (Figure 3). Univariate Cox regression analysis revealed no significant difference in the risk of death between patients of different AJCC8 TNM stage (Table II). Multivariate backward stepwise regression analysis revealed that patients who 


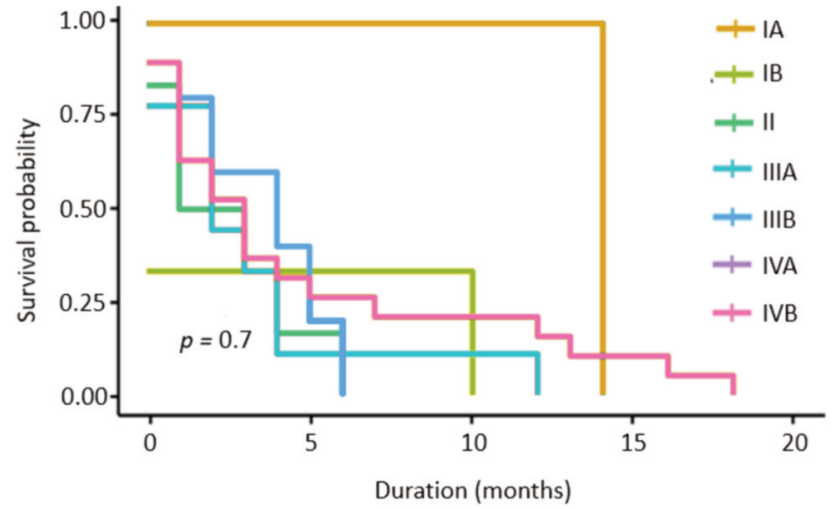

Figure 3. Kaplan-Meier curve of disease-specific survival of patients with sarcomatoid hepatocellular carcinoma in the Surveillance, Epidemiology, and End results database according to stage by the eighth edition of the American Joint Commission on Cancer classification system (19).

underwent surgery had significantly lower risk of death $(\mathrm{HR}=0.25,95 \% \mathrm{CI}=0.13-0.50 ; p<0.001$. Table II).

The OS c-index for AJCC8 was 0.577 ( $\mathrm{SE}=0.048)$.

\section{Discussion}

Major causes of HCC include hepatitis B virus-associated chronic hepatitis, chronic alcohol abuse, hepatitis $\mathrm{C}$ virus infection, non-alcoholic steatohepatitis, tobacco use, and aflatoxin exposure, amongst others $(1,24)$.

Liver resection and transplantation are considered the only HCC surgical treatments with curative-intent $(25,26)$. Liver transplantation has been associated with better 3-year (74.2\% vs. $54.4 \%, p=0.02)$ and 5 -year $(62.5 \%$ vs. $35.6 \%$, $p<0.01)$ disease-free survival rates compared with Iiver resection (27). Other non-curative treatment options include radiofrequency ablation, transarterial chemoembolization and newer chemotherapeutic agents, including sorafenib and immune checkpoint inhibitors $(7,28-34)$.

$\mathrm{HCC}$ incidence and HCC-caused mortality have been increasing over the past two decades $(8,9,35,36)$. The median survival of patients with HCC, based on SEER data, is 14 months (37). Nationwide Japanese data analysis (Liver Cancer Study Group of Japan revealed 5- and 10year OS rates of $37.9 \%$ and $16.5 \%$, respectively (12). Median survival of patients with HCC, despite being considered poor, has increased over the years due to appropriate patient selection processes and treatment with curative-intent $(5,12)$.

In the era of precision medicine and wide application of molecular profiling in a variety of malignancies, such as breast, lung and colon cancer, it is feasible to examine the validity of individualized treatment based upon tumor type.
Table II. Univariate Cox survival analysis and backward stepwise multivariate Cox regression analysis.

\begin{tabular}{lcccc}
\hline Factor & Subgroup & HR & $95 \%$ CI & $p$-Value \\
\hline Univariate & & & & \\
TNM Stage & IA & Ref & & \\
& IB & 4.31 & $0.50-37.3$ & 0.18 \\
& II & 4.94 & $0.60-40.7$ & 0.14 \\
& IIIA & 4.08 & $0.52-31.9$ & 0.18 \\
& IIIB & 2.83 & $0.34-23.6$ & 0.34 \\
& IVA & 1.61 & $0.10-25.9$ & 0.74 \\
Multivariate & IVB & 2.78 & $0.38-20.5$ & 0.32 \\
Surgery & No & Ref & & \\
& Yes & 0.25 & $0.13-0.50$ & $\mathbf{< 0 . 0 0 1}$ \\
Chemotherapy & No & Ref & & \\
& Yes & 0.62 & $0.35-1.11$ & 0.10 \\
\hline
\end{tabular}

CI: Confidence interval; HR: hazard ratio; Ref: reference. Statistically significant $p$-values are shown in bold.

The classification of patients with HCC according to histologicaI subtype and genetic profile of the tumor is important because it has been shown that histopathologic differences translate into different prognoses (14).

Sarcomatoid HCC is a discrete type of HCC in terms of its histopathology, metabolic profile and prognosis. Various alternative names have been used to describe this rare tumor, such as spindle-cell carcinoma and pseudosarcoma (38). Histopathological findings include significantly higher grade and tumor size and laboratory findings include lower total bilirubin, alanine aminotransferase, aspartate aminotransferase and lower Fibrosis-4 score compared to nonsarcomatoid HCC (10). Patients with sarcomatoid HCC, compared to non-sarcomatoid HCC, have worse overall survival as well as lower recurrence-free survival (10). Pathogenesis is unclear, but cases of sarcomatous lesions have been reported in patients with HCC after anti-neoplastic treatment modalities, such as transarterial chemoembolization or newer anti-angiogenic agents (sunitinib) (39-41). Sarcomatoid HHC has been reported in up to $1.8-2.0 \%$ of surgically treated patients with HCC $(42,43)$.

Our study is important because it summarizes relevant SEER data and investigates the performance of the AJCC8 TNM staging system in the accurate classification of patients with sarcomatoid HCC. Our analysis indicates that patients with sarcomatoid HCC are usually White males in their sixth to seventh decade of life, presenting with poorly differentiated and advanced TNM stage tumors, with a 1year OS rate of $17.4 \%$. These findings confirm the previously published data derived from the National Cancer Database by $\mathrm{Wu}$ et al. (14). The OS c-index of 0.577 indicates that the AJCC8 HCC staging is considered mediocre in predicting survival of patients with sarcomatoid 
HCC. Accurate staging guides the selection of appropriate treatment and follow-up plans and facilitates survival prognosis. AJCC remains the most commonly preferred cancer-stratification system, and is periodically reviewed and updated upon current data availability. AJCC TNM staging, in general, is expected to have moderate discriminatory potential since it is based on a small number of variables in order to remain simple and comprehensible (44).

Multivariate backward stepwise analysis revealed that surgery $(\mathrm{HR}=0.25, p<0.001)$ was associated with reduced risk of death. To our knowledge, there are no established recommendations for the appropriate management of sarcomatoid HCC. Wu et al. reported that patients with stage I or stage II malignancies were more commonly treated with curative-intent modalities (surgical resection, transplantation or ablation) and TNM staging was significantly associated with OS (14). In our study, the univariate Cox regression analysis failed to demonstrate any statistically significant association of TNM staging with increased risk of death. Nevertheless, the findings of $\mathrm{Wu}$ et al. corresponded to a subgroup of patients undergoing curative-intent treatment, whereas our analysis included the total SEER cohort. Our finding that surgery is associated with reduced risk of death should be interpreted cautiously, given the intrinsic disadvantages of the statistical method we used $(21,22)$. Patients with earlystage disease, despite receiving curative-intent treatment (approximately $70 \%$ of patients according to NCDB data), have a poor OS (14).

SEER has been used previously in the investigation of cancer risk factors, treatment and survival in the US population. Various limitations should be acknowledged during the interpretation of our study results. The SEER-9 registry covers approximately $30 \%$ of the U.S. population and patients residing in urban areas as well as foreign-born individuals constitute a relatively higher proportion compared to the corresponding percentages in the general US population (45). Notably, the SEER database does not provide detailed clinical and tumor-related data. In addition, our study was retrospective and included only 71 patients. Missing data, the presence of patients without histopathological confirmation, and incorrect coding should also be recognized as potential factors affecting our results.

\section{Conclusion}

Sarcomatoid HCC is a rare and aggresive HCC subtype and is associated with poor outcomes in terms of OS and DSS across all disease stages. Surgery seems to be of utmost importance. The eighth AJCC HCC staging system underperforms in predicting the survival of patients with sarcomatoid subtype.

\section{Conflicts of Interest}

None declared.

\section{Authors' Contributions}

Conception and design: Dimitrios Moris, Dimitrios Giannis. Acquisition, analysis, and interpretation of data: Dimitrios Giannis, Sara Morsy. Drafting of the article: Dimitrios Giannis, Georgios Geropoulos, Stepan M. Esagian, Georgios Sioutas, Dimitrios Moris. Critical revision: Dimitrios Giannis, Sara Morsy, Georgios Geropoulos, Stepan MM Esagian, Georgios Sioutas, Dimitrios Moris. Final approval: Dimitrios Giannis, Sara Morsy, Georgios Geropoulos, Stepan M. Esagian, Georgios Sioutas, Dimitrios Moris.

\section{References}

1 Singal AG, Lampertico P and Nahon P: Epidemiology and surveillance for hepatocellular carcinoma: New trends. J Hepatol 72(2): 250-261, 2020. PMID: 31954490. DOI: 10.1016/j.jhep. 2019.08.025

2 Global Burden of Disease Liver Cancer Collaboration, Akinyemiju T, Abera S, Ahmed M, Alam N, Alemayohu MA, Allen C, AlRaddadi R, Alvis-Guzman N, Amoako Y, Artaman A, Ayele TA, Barac A, Bensenor I, Berhane A, Bhutta Z, Castillo-Rivas J, Chitheer A, Choi J-Y, Cowie B, Dandona L, Dandona R, Dey S, Dicker D, Phuc H, Ekwueme DU, Zaki MES, Fischer F, Fürst T, Hancock J, Hay SI, Hotez P, Jee SH, Kasaeian A, Khader Y, Khang Y-H, Kumar GA, Kutz M, Larson H, Lopez A, Lunevicius R, Malekzadeh R, McAlinden C, Meier T, Mendoza W, Mokdad A, Moradi-Lakeh M, Nagel G, Nguyen Q, Nguyen G, Ogbo F, Patton G, Pereira DM, Pourmalek F, Qorbani M, Radfar A, Roshandel G, Salomon JA, Sanabria J, Sartorius B, Satpathy M, Sawhney M, Sepanlou S, Shackelford K, Shore H, Sun J, Mengistu DT, TopórMadry R, Tran B, Ukwaja KN, Vlassov V, Vollset SE, Vos T, Wakayo T, Weiderpass E, Werdecker A, Yonemoto N, Younis M, Yu C, Zaidi Z, Zhu L, Murray CJL, Naghavi M and Fitzmaurice $\mathrm{C}$ : The burden of primary liver cancer and underlying etiologies from 1990 to 2015 at the global, regional, and national level: Results from the global burden of disease study 2015. JAMA Oncol 3(12): 1683-1691, 2017. PMID: 28983565. DOI: 10.1001/ jamaoncol.2017.3055

3 Njei B, Rotman Y, Ditah I and Lim JK: Emerging trends in hepatocellular carcinoma incidence and mortality. Hepatology 61(1): 191-199, 2014. PMID: 25142309. DOI: 10.1002/hep.27388

4 El-Serag HB: Epidemiology of viral hepatitis and hepatocellular carcinoma. Gastroenterology 142(6): 1264-1273.e1, 2012. PMID: 22537432. DOI: 10.1053/j.gastro.2011.12.061

5 Forner A, Llovet JM and Bruix J: Hepatocellular carcinoma. Lancet 379(9822): 1245-1255, 2012. PMID: 22353262. DOI: 10.1016/S0140-6736(11)61347-0

6 Ziogas IA and Tsoulfas G: Advances and challenges in laparoscopic surgery in the management of hepatocellular carcinoma. World J Gastrointest Surg 9(12): 233-245, 2017. PMID: 29359029. DOI: 10.4240/wjgs.v9.112.233

7 Ziogas IA and Tsoulfas G: Evolving role of sorafenib in the management of hepatocellular carcinoma. World J Clin Oncol 8(3): 203-213, 2017. PMID: 28638790. DOI: 10.5306/wjco. v8.i3.203 
8 EASL Clinical Practice Guidelines: Management of hepatocellular carcinoma. J Hepatol 69(1): 182-236, 2018. PMID: 29628281. DOI: $10.1016 /$ j.jhep.2018.03.019

9. Tsilimigras DI, Bagante F, Sahara K, Moris D, Hyer JM, Wu L, Ratti F, Marques HP, Soubrane O, Paredes AZ, Lam V, Poultsides GA, Popescu I, Alexandrescu S, Martel G, Workneh A, Guglielmi A, Hugh T, Aldrighetti L, Endo I and Pawlik TM: Prognosis after resection of Barcelona Clinic Liver Cancer (BCLC) Stage 0, A, and B hepatocellular carcinoma: A comprehensive assessment of the current BCLC classification. Ann Surg Oncol 26(11): 3693-3700, 2019. PMID: 31267302. DOI: $10.1245 / \mathrm{s} 10434-019-07580-9$

10 Liao S-H, Su T-H, Jeng Y-M, Liang P-C, Chen D-S, Chen C-H and Kao J-H: Clinical manifestations and outcomes of patients with sarcomatoid hepatocellular carcinoma. Hepatology 69(1): 209-221, 2019. PMID: 30014620. DOI: 10.1002/hep.30162

11 Calderaro J, Couchy G, Imbeaud S, Amaddeo G, Letouzé E, Blanc J-F, Laurent C, Hajji Y, Azoulay D, Bioulac-Sage P, Nault $\mathrm{J}-\mathrm{C}$ and Zucman-Rossi J: Histological subtypes of hepatocellular carcinoma are related to gene mutations and molecular tumour classification. J Hepatol 67(4): 727-738, 2017. PMID: 28532995. DOI: $10.1016 /$ j.jhep.2017.05.014

12 Kudo M, Izumi N, Sakamoto M, Matsuyama Y, Ichida T, Nakashima O, Matsui O, Ku Y, Kokudo N, Makuuchi M and Liver Cancer Study Group of Japan: Survival analysis over 28 years of 173,378 patients with hepatocellular carcinoma in Japan. Liver Cancer 5(3): 190-197, 2016. PMID: 27493894. DOI: $10.1159 / 000367775$

13 Shafizadeh N and Kakar S: Hepatocellular carcinoma: Histologic subtypes. Surg Pathol Clin 6(2): 367-384, 2013. PMID: 26838979. DOI: 10.1016/j.path.2013.03.007

14 Wu L, Tsilimigras DI, Farooq A, Hyer JM, Merath K, Paredes AZ, Mehta R, Sahara K, Shen F and Pawlik TM: Management and outcomes among patients with sarcomatoid hepatocellular carcinoma: A population-based analysis. Cancer 125(21): 37673775, 2019. PMID: 31299092. DOI: $10.1002 /$ cncr.32396

15 Watanabe Y, Matsumoto N, Ogawa M, Moriyama M and Sugitani M: Sarcomatoid hepatocellular carcinoma with spontaneous intraperitoneal bleeding. Intern Med 54(13): 16131617, 2015. PMID: 26134192. DOI: 10.2169/internalmedicine. 54.3523

16 Maeda T, Adachi E, Kajiyama K, Takenaka K, Sugimachi K and Tsuneyoshi M: Spindle cell hepatocellular carcinoma. A clinicopathologic and immunohistochemical analysis of 15 cases. Cancer 77(1): 51-57, 1996. PMID: 8630939. DOI: $10.1002 /($ SICI) $1097-0142(19960101) 77: 1<51::$ AID CNCR10>3.0.CO;2-7

17 Nagtegaal ID, Odze RD, Klimstra D, Paradis V, Rugge M, Schirmacher P, Washington KM, Carneiro F, Cree IA and WHO Classification of Tumours Editorial Board: The 2019 WHO Classification of Tumours of the Digestive System. Histopathology 76(2): 182-188, 2020. PMID: 31433515. DOI: 10.1111/his. 13975

18 American Joint Committee on Cancer I SEER Training. Available at: https://training.seer.cancer.gov/staging/systems/ ajcc/ [Last accessed on August 31 st , 2020]

19 Amin MB, Greene FL, Edge SB, Compton CC, Gershenwald JE, Brookland RK, Meyer L, Gress DM, Byrd DR and Winchester DP: The eighth edition AJCC Cancer Staging Manual: Continuing to build a bridge from a population-based to a more "personalized" approach to cancer staging. CA Cancer J Clin 67(2): 93-99, 2017. PMID: 28094848. DOI: 10.3322/caac.21388

20 Uno H, Cai T, Pencina MJ, D'Agostino RB and Wei LJ: On the $\mathrm{C}$-statistics for evaluating overall adequacy of risk prediction procedures with censored survival data. Stat Med 30(10): 11051117, 2011. PMID: 21484848. DOI: 10.1002/sim.4154

21 Harrell FE, Lee KL and Mark DB: Multivariable prognostic models: issues in developing models, evaluating assumptions and adequacy, and measuring and reducing errors. Stat Med 15(4): 361-387, 1996. PMID: 8668867. DOI: 10.1002/(SICI) 1097-0258(19960229) 15:4<361::AID-SIM168>3.0.CO;2-4.

22 Thao LTP and Geskus R: A comparison of model selection methods for prediction in the presence of multiply imputed data. Biom J 61(2): 343-356, 2019. PMID: 30353591. DOI: 10.1002/ bimj. 201700232

23 Harrell FE: Regression Modeling Strategies - With Applications to Linear Models, Logistic Regression, and Survival Analysis. Springer. Available at: https://www.springer.com/gp/book/ 9781441929181 [Last accessed on 30th January 2020]

24 Dimitroulis D, Damaskos C, Valsami S, Davakis S, Garmpis N, Spartalis E, Athanasiou A, Moris D, Sakellariou S, Kykalos S, Tsourouflis G, Garmpi A, Delladetsima I, Kontzoglou K and Kouraklis G: From diagnosis to treatment of hepatocellular carcinoma: An epidemic problem for both developed and developing world. World J Gastroenterol 23(29): 5282-5294, 2017. PMID: 28839428. DOI: 10.3748/wjg.v23.i29.5282

25 Clavien P-A, Lesurtel M, Bossuyt PMM, Gores GJ, Langer B, Perrier A and OLT for HCC Consensus Group: Recommendations for liver transplantation for hepatocellular carcinoma: An international consensus conference report. Lancet Oncol 13(1): e11-22, 2012. PMID: 22047762. DOI: 10.1016/ S1470-2045(11)70175-9

26 Moris D, Tsilimigras DI, Kostakis ID, Ntanasis-Stathopoulos I, Shah KN, Felekouras E and Pawlik TM: Anatomic versus nonanatomic resection for hepatocellular carcinoma: A systematic review and meta-analysis. Eur J Surg Oncol 44(7): 927-938, 2018. PMID: 29751946. DOI: 10.1016/j.ejso.2018.04.018

27 Menahem B, Lubrano J, Duvoux C, Mulliri A, Alves A, Costentin C, Mallat A, Launoy $G$ and Laurent A: Liver transplantation versus liver resection for hepatocellular carcinoma in intention to treat: An attempt to perform an ideal meta-analysis. Liver Transpl 23(6): 836-844, 2017. PMID: 28295992. DOI: $10.1002 / 1 \mathrm{t} .24758$

28 Hilmi M, Neuzillet C, Calderaro J, Lafdil F, Pawlotsky J-M and Rousseau B: Angiogenesis and immune checkpoint inhibitors as therapies for hepatocellular carcinoma: current knowledge and future research directions. J Immunother Cancer 7(1): 333, 2019. PMID: 31783782. DOI: 10.1186/s40425-019-0824-5

29 Faivre S, Rimassa L and Finn RS: Molecular therapies for HCC: Looking outside the box. J Hepatol 72(2): 342-352, 2020. PMID: 31954496. DOI: 10.1016/j.jhep.2019.09.010

30 Cheng A-L, Hsu C, Chan SL, Choo S-P and Kudo M: Challenges of combination therapy with immune checkpoint inhibitors for hepatocellular carcinoma. J Hepatol 72(2): $307-$ 319, 2020. PMID: 31954494. DOI: 10.1016/j.jhep.2019.09.025

31 Moris D, Rahnemai-Azar AA, Zhang X, Ntanasis-Stathopoulos I, Tsilimigras DI, Chakedis J, Argyrou C, Fung JJ and Pawlik TM: Program death-1 immune checkpoint and tumor microenvironment in malignant liver tumors. Surg Oncol 26(4): 423-430, 2017. PMID: 29113661. DOI: 10.1016/j.suronc.2017.08.005 
32 Tsilimigras DI, Bagante F, Moris D, Merath K, Paredes AZ, Sahara K, Ratti F, Marques HP, Soubrane O, Lam V, Poultsides GA, Popescu I, Alexandrescu S, Martel G, Workneh A, Guglielmi A, Hugh T, Aldrighetti L, Endo I and Pawlik TM: Defining the chance of cure after resection for hepatocellular carcinoma within and beyond the Barcelona Clinic Liver Cancer guidelines: A multi-institutional analysis of 1,010 patients. Surgery 166(6): 967-974, 2019. PMID: 31606196. DOI: 10.1016/j.surg.2019.08.010

33 Moris D, Burkhart RA, Beal EW and Pawlik TM: Laparoscopic hepatectomy for hepatocellular carcinoma: are oncologic outcomes truly superior to an open approach? Hepatobiliary Surg Nutr 6(3): 200-202, 2017. PMID: 28653005. DOI: 10.21037/hbsn.2017.03.09

34 Vibert E, Schwartz M and Olthoff KM: Advances in resection and transplantation for hepatocellular carcinoma. J Hepatol 72(2): 262-276, 2020. PMID: 31954491. DOI: 10.1016/j.jhep. 2019.11.017

35 Rebouissou S, Nault J-C: Advances in molecular classification and precision oncology in hepatocellular carcinoma. J Hepatol 72(2): 215-229, 2020. PMID: 31954487 DOI: 10.1016/j.jhep. 2019.08.017

36 Beal EW, Tumin D, Kabir A, Moris D, Zhang X-F, Chakedis J, Washburn K, Black S, Schmidt CM and Pawlik TM: Trends in the mortality of hepatocellular carcinoma in the United States. J Gastrointest Surg 21(12): 2033-2038, 2017. PMID: 28785936. DOI: $10.1007 / \mathrm{s} 11605-017-3526-7$

37 Shah C, Mramba LK, Bishnoi R, Bejjanki H, Chhatrala HS and Chandana SR: Survival differences among patients with hepatocellular carcinoma based on the stage of disease and therapy received: Pre and post sorafenib era. J Gastrointest Onco 8(5): 789-798, 2017. PMID: 291846. DOI: 10.21037/jgo. 2017.06.16

38 Wang Q-B, Cui B-K, Weng J-M, Wu Q-L, Qiu J-L, Lin X-J: Clinicopathological characteristics and outcome of primary sarcomatoid carcinoma and carcinosarcoma of the liver. J Gastrointest Surg 16(9): 1715-1726, 2012. PMID: 22767081. DOI: $10.1007 / \mathrm{s} 11605-012-1946-y$
39 Marijon H, Dokmak S, Paradis V, Zappa M, Bieche I, Bouattour $\mathrm{M}$, Raymond $\mathrm{E}$ and Faivre S: Epithelial-to-mesenchymal transition and acquired resistance to sunitinib in a patient with hepatocellular carcinoma. J Hepatol 54(5): 1073-1078, 2011. PMID: 21145871. DOI: 10.1016/j.jhep.2010.11.011

40 Kojiro M, Sugihara S, Kakizoe S, Nakashima O and Kiyomatsu $\mathrm{K}$ : Hepatocellular carcinoma with sarcomatous change: A special reference to the relationship with anticancer therapy. Cancer Chemother Pharmacol 23 Suppl: S4-8, 1989. PMID: 2466583. DOI: $10.1007 / B F 00647229$

$41 \mathrm{Yu}$ Y, Zhong Y, Wang J and Wu D: Sarcomatoid hepatocellular carcinoma (SHC): a case report. World J Surg Oncol 15(1): 219 , 2017. PMID: 29233162. DOI: 10.1186/s12957-017-1286-1

42 Giunchi F, Vasuri F, Baldin P, Rosini F, Corti B, D’Errico-Grigioni A: Primary liver sarcomatous carcinoma: Report of two cases and review of the literature. Pathol - Res Pract 209(4): 249-254, 2013. PMID: 23484778. DOI: 10.1016/j.prp.2013.01.005

43 Seok JY, Kim YB. [Sarcomatoid hepatocellular carcinoma]. Korean J Hepatol 16(1): 89-94, 2010. PMID: 20375648. DOI: 10.3350/kjhep.2010.16.1.89

44 Kim Y, Moris DP, Zhang X-F, Bagante F, Spolverato G, Schmidt C, Dilhoff $M$ and Pawlik TM: Evaluation of the $8^{\text {th }}$ edition American Joint Commission on Cancer (AJCC) staging system for patients with intrahepatic cholangiocarcinoma: A Surveillance, Epidemiology, and End Results (SEER) analysis. J Surg Oncol 116(6): 643-650, 2017. PMID: 28608424. DOI: $10.1002 /$ jso. 24720

45 Rahman R, Simoes EJ, Schmaltz C, Jackson CS and Ibdah JA: Trend analysis and survival of primary gallbladder cancer in the United States: A 1973-2009 population-based study. Cancer Med 6(4): 874-880, 2017. PMID: 28317286. DOI: 10.1002/ cam4.1044

Received September 11, 2020

Revised October 11, 2020

Accepted October 13, 2020 